\title{
Careful Co-Planning for Effective Team Teaching in Mathematics
}

\author{
Alison S Marzocchi $\left.{ }^{1 \star} \mathbb{(}\right)$, Bridget K Druken ${ }^{1}\left[\right.$, Michelle V Brye ${ }^{1}(\mathbb{C}$
}

${ }^{1}$ California State University, Fullerton, CA, USA

*Corresponding Author: amarzocchi@fullerton.edu

Citation: Marzocchi, A. S., Druken, B. K., \& Brye, M. V. (2021). Careful Co-Planning for Effective Team Teaching in Mathematics. International Electronic Journal of Mathematics Education, 16(3), em0663. https://doi.org/10.29333/iejme/11299

\section{ARTICLE INFO}

Received: 22 Jan. 2021

Accepted: 14 Sep. 2021

\begin{abstract}
This paper reports on a semester-long co-teaching investigation in which three mathematics teacher educators in the USA themselves enacted a co-plan/co-teach credentialing model in the context of a mathematics content course for future elementary teachers. The mathematics teacher educators sought to examine the co-planning practices for improving the team teaching co-teaching strategy. Data were collected from the mathematics teacher educators over fifteen weeks, including twice-weekly journal entries and classroom observation protocols. Utilizing a first-person research study design, the mathematics teacher educators found that a coplanning strategy could be used to maximize resources and improve lesson cohesion during team taught lessons. In particular, the mathematics teacher educators used co-planning meetings to divide lesson responsibilities by learning goal or by task. In this novel approach to mathematics teacher educator training, we describe the coplanning strategy along with its expansion, implementation, benefits, and limitations, and argue for its use in coteachers' co-planning repertoire.
\end{abstract}

Keywords: co-teaching, co-planning, team teaching, cooperative teaching, mathematics teacher educators, mathematics education

\section{INTRODUCTION}

Credential programs in the USA are increasingly shifting from a model of observation and replication towards a model of gradual induction (Bacharach et al., 2010; Hartigan, 2014; Hiesh \& Nguyen, 2015; Yopp et al., 2014). Gradual induction models allow teacher candidates to play instructional roles alongside mentor teachers from the start of the credential partnership, rather than beginning the credential program in an observation role. While different program formats may accomplish gradual induction, a co-plan/co-teach model provides a teacher candidate opportunities to design collaborative lessons, teach side-by-side, and reflect on instruction with an experienced mentor teacher (Yopp et al., 2014).

Recent research has documented educators' efforts of moving towards co-teaching in teacher preparation programs (Yopp et al., 2014). However, shifting to co-plan/co-teach formats for teacher preparation is not often coupled with professional development opportunities for teacher educators to learn the model themselves. Duran et al. (2019) note that for teachers to appreciate the benefits of co-teaching, they must themselves have opportunities to experience co-teaching. Inspired by Kamen et al. (2011) who seek to 'walk the talk' in their lesson study work with teacher educators, our work sought to address the lack of coplan/co-teach experience among teacher educators by designing and researching a semester-long investigation in which we replicated our university's co-plan/co-teach credentialing model for ourselves.

The co-plan/co-teach credentialing model at our university matches a teacher candidate (TC) (sometimes referred to as a student teacher) with an experienced mentor teacher (MT) (sometimes referred to as the cooperating or master teacher) and provides a university clinical coach (CC) (sometimes referred to as the field supervisor or student teaching supervisor) for cyclical feedback through video and site observations. We replicated this model in an elementary mathematics content course for university undergraduate pre-service teachers who intend to enroll in a multiple subjects credential program for teaching elementary school (a credential to teach students aged five to twelve).

Our co-teaching involved each of the three authors, who are all mathematics teacher educators (MTEs), taking on a role in the credential partnership: the first author served as TC, the second author served as MT and the third author served as CC. This process was novel at our university since at the time of our study university educators had not intentionally experienced the coteaching model as learners themselves. We recognize that our design was not a perfect replication of the model because the author serving as the TC likely had more teaching experience than a novice TC in a credential program. However, co-teaching in a university setting was a new experience for our TC and MT and knowledge could be gained on our two research questions: How 
do co-teachers utilize the co-planning process for team teaching? and, What benefits do co-teachers report when using a coplanning strategy for team teaching?

In addition to benefits for our own professional development around co-planning and co-teaching, we conjectured that experiencing the co-plan/co-teach format would support future teachers by modeling this pedagogy before they entered their credential program. What we mean by this is that the students in our class, who would eventually enter a co-plan/co-teach credential program, would see the enactment of co-teaching strategies on a twice-weekly basis in our mathematics content course. This would increase their familiarity with co-teaching before enacting it themselves in their future teaching credential program.

The aim of this paper is to report on findings from a first-person research study (Ball, 2000) of our co-plan/co-teach experience in the university mathematics setting. This study was part of a larger project that examined MTEs' reported benefits, limitations, and considerations of different co-teaching strategies. Through the larger investigation, we deepened a co-planning strategy for improved team teaching. In doing so, we address one of Pearl et al.'s (2012) key elements for change related to co-teaching: determining important considerations in planning for co-teaching. Thus, this paper reports on a co-teaching strategy that involves MTEs' careful co-planning around learning goals or tasks to reduce redundancies in their questioning and to promote equitable visitation of students. We address the research questions: How do co-teachers utilize the co-planning process for team teaching? What benefits do co-teachers report when using a co-planning strategy for team teaching?

We contribute to the literature on co-teaching not only through our higher education context, but also by reporting on the under-researched co-planning aspect of co-teaching (Pratt et al., 2017). Elsewhere, we report on findings around other co-teaching strategies (Authors, under review). Here, we report on improved team teaching through careful co-planning. We share how the cyclical and focused investigation of our co-teaching resulted in a strategy for improved team teaching through careful coplanning.

\section{LITERATURE REVIEW}

Cook and Friend (1995) are credited with coining the term co-teaching, which they define as 'two or more professionals delivering substantive instruction to a diverse, or blended, group of students in a single physical space.' Teacher learning through co-teaching has been investigated both in the United States, where our work is situated (e.g., Hiesh \& Nguyen, 2015), and internationally (Murphy \& Scantlebury, 2010; Rytivaara \& Kershner, 2012). Co-teaching can be seen with practicing K-12 teachers and through coursework for future teachers but has not been widely implemented by MTEs at the university level. Our co-teaching perspective takes on the view that learning how to teach mathematics involves a process of enculturation into a community of mathematics teachers. In our case, MTEs deepen their shared understanding, tools, and language around co-planning and coteaching through a semester-long investigation in a mathematics content course for future elementary teachers.

\section{Benefits of Co-teaching}

Many benefits of co-teaching have been described. This includes benefits for students such as an increased ability to meet individual students' needs (Bacharach \& Heck, 2007; Bacharach et al., 2010; Cook \& Friend, 1995; Dynak et al., 1997; Ferguson \& Wilson, 2011; Graziano \& Navarrete, 2012) and particularly the needs of diverse learners (Dynak et al., 1997, Hoppey et al., 2004), as well as improved outcomes for students in co-taught classes (Bacharach et al., 2010; Duran et al., 2019). There are also benefits for teachers including the encouragement of varied pedagogy (Bacharach \& Heck, 2007; Bacharach et al., 2010; Birrell \& Bullough, 2005; Duran et al., 2019; Graziano \& Navarrete, 2012) and increased engagement in reflection (Bacharach \& Heck, 2007; Duran et al., 2019; Graziano \& Navarrete, 2012). Co-teaching also promotes collaboration (Duran et al., 2019) and can serve as professional development opportunities for co-teachers (Bacharach \& Heck, 2007; Graziano \& Navarrete, 2012; Hiesh \& Nguyen, 2015). These benefits provide reasons for continuing the use of co-teaching due to its ability to support both students and teachers.

Yet less is known about MTEs' particular experiences co-teaching due to minimal research on co-teaching in mathematics (Rexroat-Frazier et al., 2019). Increasing MTEs' experiences with co-teaching in teacher preparation courses could benefit MTEs and pre-service teachers alike. Thousand et al. (2006, p. 241), who provide tips for successful collaborative planning and teaching in higher education, explain:

First, coteaching provides a greater opportunity to capitalize on the unique, diverse and specialized knowledge of each instructor. Second, coteaching allows students to experience and imitate the cooperative and collaborative skills that teachers show when they coteach.

Exposure to collaborative teaching is particularly beneficial for pre-service teachers who will be expected to teach similarly in their credential programs and careers. Thus, increasing MTEs' use of co-teaching in courses for pre-service teachers would increase their exposure before co-teaching in future credential programs (Bacharach \& Heck, 2007; Thousand et al., 2006).

\section{Co-Teaching Strategies}

Researchers have detailed several pedagogical strategies for implementing co-teaching (Bacharach \& Heck, 2007; Bacharach et al., 2010; Cook \& Friend, 1995; Dynak et al., 1997; Ferguson \& Wilson, 2011; Graziano \& Navarrete, 2012; Thousand et al., 2006). Frequently cited strategies include one teach one observe, one teach one assist, station teaching, parallel teaching, supplemental teaching, alternative (differentiated) teaching and team teaching (see Table 1). This set of strategies put forth by Bacharach et al. (2010) is a foundational approach to using co-teaching as a student teaching model in the United States. It began with funding 
Table 1. Description of seven co-teaching instructional strategies, informed by Bacharach et al. (2010)

\begin{tabular}{ll}
\hline Co-teaching Strategy & Description \\
\hline One teach, one observe & $\begin{array}{l}\text { one teacher is responsible for leading instruction while the other teacher collects targeted observation data on } \\
\text { students or teaching }\end{array}$ \\
\hline One teach, one assist & $\begin{array}{l}\text { one teacher assumes the lead and the other teacher helps in a particular way, such as with classroom management, } \\
\text { distributing/collecting materials or answering student questions }\end{array}$ \\
\hline Station teaching & $\begin{array}{l}\text { the room is divided and students rotate among non-hierarchical stations, with some stations led by co-teachers and } \\
\text { others as independent stations }\end{array}$ \\
\hline Parallel teaching & both teachers teach the same lesson concurrently to half of the students to lower the student-to-teacher ratio \\
\hline Supplemental teaching & $\begin{array}{l}\text { one teacher assumes the primary instructional role and the second teacher works separately with a purposefully } \\
\text { selected small group of students who are still striving to learn the content or are ready for extension }\end{array}$ \\
\hline $\begin{array}{l}\text { Alternative teaching } \\
\text { (differentiated teaching) }\end{array}$ & $\begin{array}{l}\text { both teachers teach the same learning goal but use different approaches, such as a visual approach versus a } \\
\text { kinesthetic approach }\end{array}$ \\
\hline Team teaching (shared or & two teachers fluidly share the delivery of instruction \\
tag teaching) &
\end{tabular}

from the United States Department of Education fifteen years ago, has since been presented at many state and national conferences, and has been used to develop training programs in co-teaching in over 35 states in the USA. Some states currently mandate or recommend the use of this model in student teaching (Friend et al., 2015).

The framework of co-teaching strategies served as our guide as we designed our semester-long co-plan/co-teach investigation (Bacharach et al., 2010). The selection of different co-teaching strategies depends on specific learning goals and classroom situations (Ferguson \& Wilson, 2011; Thousand et al., 2006). The one teach, one observe strategy allows one teacher to take the primary role in delivering instruction and implementation of the lesson for the class while the other teacher takes responsibility for observing and taking data on the class. One teach, one assist is a similar strategy in that one teacher takes the primary role of delivering instruction to the whole class; however, the other teacher takes the responsibility to monitor student learning and assist as needed. In station teaching, each teacher presents a part of the content to one part of the group, and then repeats that lesson to the other group(s). Parallel teaching requires both teachers to plan the instruction together to ensure that both teachers are presenting the same material in the same way. In supplemental teaching, one teacher works with students who need reteaching of a concept while the other teacher works with the rest of the students on enrichment. Alternative teaching allows each teacher to take a group of students and use an instructional approach that best fits the needs or learning style of the group. For team teaching, both teachers take an interactive approach and lead instructional activities together.

\section{A Focus on Team Teaching}

Though our larger study investigated affordances and limitations of the seven co-teaching strategies detailed in Table 1 (see Druken \& Marzocchi, under review), this paper focuses on team teaching and, in particular, co-planning for effective team teaching. Thousand et al. (2006, p. 242) define team teaching as a co-teaching strategy in which both teachers 'jointly plan, teach, assess and assume responsibility for all of the students in the classroom.' Ideally, either teacher can assume a leadership role depending on in-the-moment need. This intimate sharing of the classroom, students and content requires trust, time for coordination and capitalizing on each teacher's strengths and expertise (Thousand et al., 2006).

Through our semester-long co-teaching investigation utilizing the seven co-teaching strategies, we found that much of our planning time, debriefing, and interactions with the CC were focused on strategies for effective team teaching. This is not surprising, given the documented complexities in achieving effective team teaching (Thousand et al., 2006). This paper reports on our investigation of the critical components of co-planning for successful team teaching.

\section{METHODS}

With a goal of gaining a nuanced understanding of team teaching under a co-teaching credentialing model, we deeply investigated our own practice during a fifteen week semester-long mathematics content course for future elementary teachers in the USA. Forty undergraduates were enrolled in the course which met for two 75-minute class sessions each week. After each class session, the MT and TC independently journaled. The CC journaled for targeted lessons, as described below. The MT and TC met twice each week. One 120-minute weekly meeting was reserved for co-planning which involved activities such as defining learning goals, designing lesson activities and assessments, selecting co-teaching strategies, determining roles for each co-teacher, etc. The CC was involved in planning meetings for targeted lessons, as described below. The second 120-minute weekly meeting was reserved for research which involved activities such as reviewing journal entries, forming initial conjectures, reading and discussing literature, etc.

Our study was designed as a first-person research study, in which the researcher is also the instructor (Ball, 2000). First-person research studies are highly contextualized, supporting deep understanding from an insider's perspective (Ball, 2000). First-person research was an appropriate study design because we sought to deepen MTEs' knowledge of co-teaching strategies, rather than study the effectiveness of a program or impact on students. For instance, we did not seek to claim that co-taught courses are more effective than solo-taught courses. Instead, through this design, we are able to present rich findings based on our firsthand experience implementing and researching co-teaching strategies, which will serve as a stepping stone to larger co-teaching research studies. Additionally, first person research has been used to articulate co-teaching in terms of activity theory (Roth et al., 2002). 


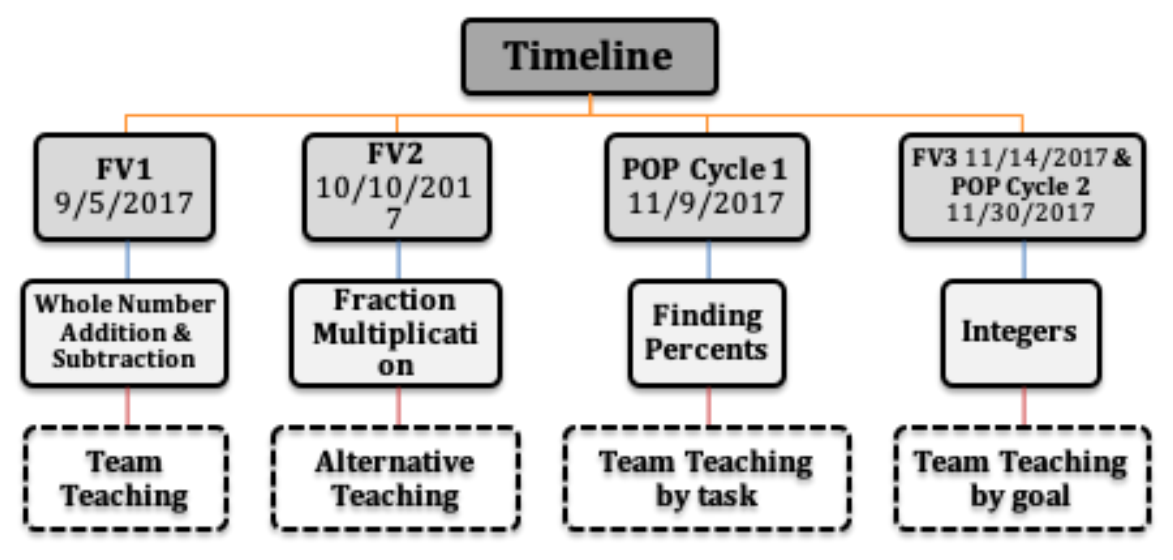

Figure 1. Timeline for data collection included three Focused Visits and two Pre-Observation-Post (POP) Cycles

A co-plan/co-teach model is used at our large public North American university for both the multiple- and single-subject credential teacher preparation programs. In this model, the MT and TC engage in co-planning and co-teaching with the support of a CC. Throughout the semester, the TC meets with the CC to discuss goals, strategies, and reflection of lessons. The CC communicates regularly with the TC and MT to provide professional guidance and coaching. Additionally, the CC ensures that there is adequate communication among the TC, the MT and the CC. Our investigation of co-teaching sought to mimic the credential program format for ourselves, while simultaneously investigating how to successfully plan for the team teaching strategy.

\section{Participants}

The three authors identify as cis-gendered white women. All have experience coaching TCs in their field placements as well as teaching mathematics content and/or methods courses for future teachers. In addition, two authors each have five years of K- 12 teaching experience: the first at the high school level (students age 14-18) and the third at the elementary level (students age 511). To design an investigation which replicated the co-plan/co-teach model, the first author served as the TC as she had not previously taught the course, the second author served as the MT because she had taught the course before, and the third author served as the $\mathrm{CC}$ because she had extensive experience in this role.

It is important to note that the authors had prior experiences collaborating together. These collaborations include (1) a lesson study project involving all three authors (Druken et al., 2020) and (2) the co-planning of a different mathematics content course involving the first two authors. With prior experience collaborating, our team began this study with previously-established working relationships and had already reported bonding as a professional community, building trust, and aligning educational goals (Druken et al., 2020). This contrasts other studies which describe co-teaching efforts among teachers who had little experience working together (e.g., Ferguson \& Wilson, 2011).

\section{Data Collection}

Mimicking the university's co-plan/co-teach credential model, the CC observed the MT and TC throughout the fifteen-week long semester: early September, early October, early November, and late November. For each observation, we used formats, forms, and structures of the credential program.

Primary data sources include the MT and TC's twice-weekly journal entries (Ferguson \& Wilson, 2011; Graziano \& Navarrete, 2012) with targeted reflections on the co-teaching process; MT and TC journal entries following the targeted co-planning, coaching, and research meetings; five co-planning forms (described below); two mathematics-specific observation report forms (the Mathematics Classroom Observation Practices Protocol (MCOPP)) (Gleason et al., 2015); and five CC journal entries following the five classroom observations. Secondary data sources include video recordings of two targeted lessons and lesson planning materials.

The following describes the structure of the five classroom visits in which the CC coached the MT and TC. Following the structure of our credential program, three of these visits followed a Focused Visit format and two followed a PreObservation/Observation/Post-Observation Cycles (POP) format (Titan EDUCATOR, n.d.). See Figure 1 for the timeline of these visits.

During a Focused Visit (Appendix A), the CC meets with the TC to select a target or focus area. For example, a focus might be on examining ways to engage and support all students in learning the content. The POP cycle (Appendix B) is broken into three phases, the pre-observation phase, during observation phase, and the post observation phase. In the pre-observation phase, the CC meets with the TC prior to instruction to discuss a focus for the planned observation. During the observation phase, the CC attends the lesson and provides written feedback to the TC while the lesson is video recorded. During the post observation phase, the CC provides feedback after both have had time to watch the video recording and reflect on the lesson. The POP cycle form is used to document this three-phase process. To summarize: 
- For the three Focused Visits:

- TC and CC decided on a specific mentoring focus, hence the term 'focused visit.'

- CC helped TC brainstorm and plan for an upcoming lesson.

- Focused Visit form captured the process.

- For the two POP Cycles:

- TC sent CC a lesson plan ahead of time.

- CC reviewed the lesson plan to provide feedback prior to teaching.

- Lesson was video recorded and observed by CC in person.

○ TC, MT, and CC team debriefed after lesson.

- TC watched the video of the lesson, reflected on the instruction and sent overall reflection notes back to CC.

o POP form captured the process.

\section{Data Analysis}

To better understand the implementation of co-teaching strategies, we first began by reviewing the Focused Visit and POP observation forms. Forms were coded inductively based on patterns emerging from the data and revealed that team teaching was the strategy most often targeted during coaching sessions (Hatch, 2002). In particular, the MT and TC often drew upon the CC's expertise on effective co-planning strategies for successful team teaching since this was the most challenging co-teaching strategy for us. We then reanalyzed all coaching and observation forms and analyzed all relevant journal entries related to the initial team teaching theme. All entries that alluded to or made direct reference to the team teaching co-teaching strategy were then pooled into a document and coded based on the nature of the team teaching reference. For example, when a coaching form referenced an integer lesson that made use of team teaching, we prioritized examining our individual journal reflections that were written directly after teaching the integer lesson and coded instances of team teaching.

The pooled excerpts were then arranged in chronological order to investigate the evolution of our team teaching over time. For example, early journal references to team teaching that mentioned general successes and challenges of sharing the lesson were coded, along with later entries about how we shared the lesson by dividing tasks or learning goals while planning together. Once chronological, inductive analysis techniques were used on the data to uncover emerging themes around team teaching (Hatch, 2002), including: defining the strategy, the emerging development of the strategy, benefits of the strategy, and how the strategy compares to existing strategies. This led us to reexamine data for any evidence that described planning for classroom rotations with particular goals. Secondary sources, such as lesson plan materials, served to provide additional detail surrounding the lesson reflections in journal and coaching documents. For instance, if a journal entry referenced an aspect of a lesson on percents, the percents lesson plan was revisited for context on learning goals, learning activities, mathematical tasks, teacher questioning, etc.

To uphold reliability standards, each author journaled independently. The findings reported below were triangulated across authors. Secondary data sources, both video recordings and lesson planning materials, were consulted by the authors to validate specific claims about lessons such as the learning goals or the role assumed by each co-teacher.

\section{RESULTS}

A primary outcome of this study was the attention paid to careful co-planning for effective team teaching in the context of a university mathematics course for future teachers. For context, we first report on the emergence of this co-planning strategy. We then address our two research questions, How do co-teachers utilize the co-planning process for team teaching? and, What benefits do co-teachers report when using a co-planning strategy for team teaching? To do so, we first share two ways to divide a team-taught lesson through co-planning. Then, we describe the co-planning strategy's benefits with respect to lesson planning and teaching.

\section{A Need for Careful Co-Planning}

Throughout the semester as we assumed the roles of TC, MT, and CC in our investigation, we found ourselves focusing on how to effectively co-plan for team teaching. A co-planning strategy emerged which involved pre-dividing the lesson among the coteachers so that each teacher focused on a subset of the lesson content. Exactly how we would partition different aspects of the lesson served as the focus of many coaching forms, observation forms, and journal entries.

In our task-based, student-centered classroom, pre-service teachers often worked in groups. The MT and TC both rotated the room answering questions and informally assessing understanding. However, we reported asking redundant questions or revisiting the same groups of pre-service teachers. This aligns with Pearl et al.'s (2012, p. 576) finding that participants in their study noted a challenge in finding 'meaningful roles for both teachers.' The first author of our study, while serving in the role of TC, described the need to address the role for both teachers on a Focused Visit form:

We realized that with co-teaching strategies such as Parallel or Station Teaching, it is predetermined which [pre-service teachers] are assigned to which teacher. However, when we are implementing Team Teaching or One Teach strategies, the two of us have the whole class in front of us and it isn't clear who should check in with which groups. (TC 9/5/17) 


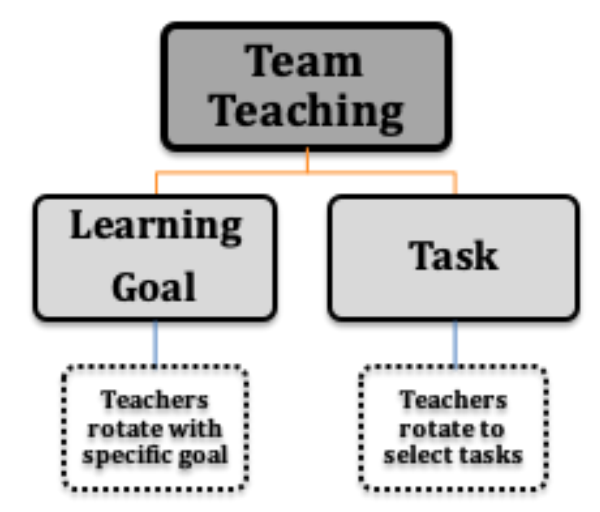

Figure 2. Breakdown of lesson division by learning goal or by task

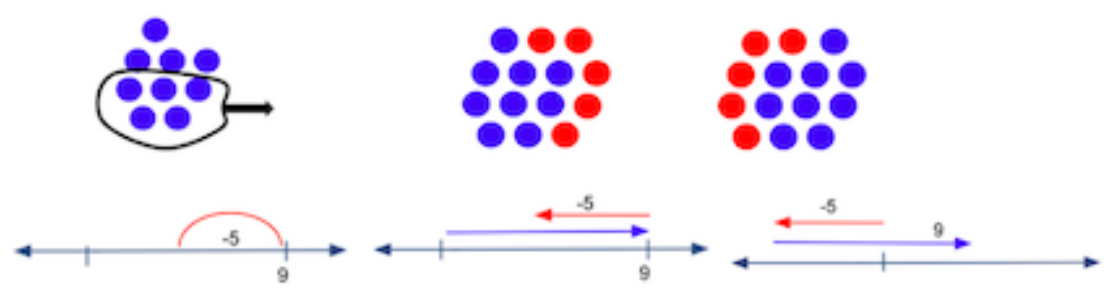

Figure 3. Integer addition and subtraction using chips (blue = positive 1 , red = negative 1 ) and number lines

In a post-lesson reflection, the TC posed, 'an idea that we might want to try in future lessons for co-teaching: rather than splitting students or tasks, perhaps we can try splitting "big ideas" or "learning goals" (TC 11/9/17). The MT responded, 'I think this is a great reflection, [TC]! I have never thought of splitting up the learning goals like that, and using that for our interactions with [pre-service teachers] who are engaging with the tasks' (MT 11/9/17, emphasis in original). This would allow the TC and MT to avoid redundancy because even if they visit the same group, they are each asking different questions.

\section{A Solution for Careful Co-Planning}

As we worked to improve our team teaching throughout the semester, we noted that team taught lessons were improved when the MT and TC divided the lesson by task or by learning goal. That is, we noted improvements through using co-planning to intentionally coordinate rotations among pre-service teachers as to reduce redundant or inequitable group visits. Our study revealed two ways to divide the lesson - by learning goal and by task (see Figure 2). To address our first research question, How do co-teachers utilize the co-planning process for team teaching?, we define and exemplify each of these dividing methods below.

Lesson Division by Learning Goal. When dividing a lesson by learning goal, each co-teacher rotates with a predetermined learning goal or big idea of the lesson in mind. As the co-teachers rotate to groups, they assess student understanding and ask questions targeted towards their particular goal. For example, one co-teacher might rotate to check the use of three specific vocabulary words while the other co-teacher might rotate to ask for the real-life meaning of different points on a graph. Alternatively, one co-teacher might rotate to look for a common (mis)conception while the other co-teacher might rotate to ask groups to explain their conclusion. This version of lesson division helps to eliminate redundancies in co-teachers' questions because each co-teacher tailors her questions to a different goal. The co-teachers can also achieve a greater depth of questioning due to their specialized focus, which ultimately helps teachers to focus on student learning (Scantlebury et al., 2008).

An example of lesson division by goal can be seen in a lesson on integers from our mathematics content class. Our learning goals were: (1) Pre-service teachers will be able to model integer number sentences using two types of diagrams -- linear (number lines) and discrete (chip counters), and (2) Pre-service teachers will be able to apply real-life contexts to integer number sentences. During the lesson, groups of pre-service teachers were given three integer number sentences and asked to model each with both a chip model and a number line model (see Figure 3 ).

$$
9-5=? \quad 9+(-5)=? \quad(-5)+9=?
$$

Pre-service teachers were also asked, How can each number sentence be connected to a real-life context? Prior to the lesson, co-teachers decided that the MT would rotate with the goal of supporting pre-service teachers in their use of the two models, while the TC would rotate with the goal of supporting pre-service teachers in connecting each number sentence to a real-life context.

During group work, the MT rotated to check for the model usage. If she saw one group relied heavily on one model, she coached them towards using the other. At the same time, the TC asked pre-service teachers to explain why their contexts were different even though the expressions were numerically equivalent. The TC and MT purposefully selected pre-service teachers' solutions to share with the whole class, targeted to their respective goals of the lesson. The TC reflected in her journal entry following this lesson that, 'This worked out really nicely. We were able to intentionally question groups, deliberately call certain groups up to the front to share solutions and help make sure each group was on target towards the learning goals' (TC 11/13/17). Dividing the lesson by goal encouraged us to anticipate more pre-service teachers' solutions and prepare targeted questions. 

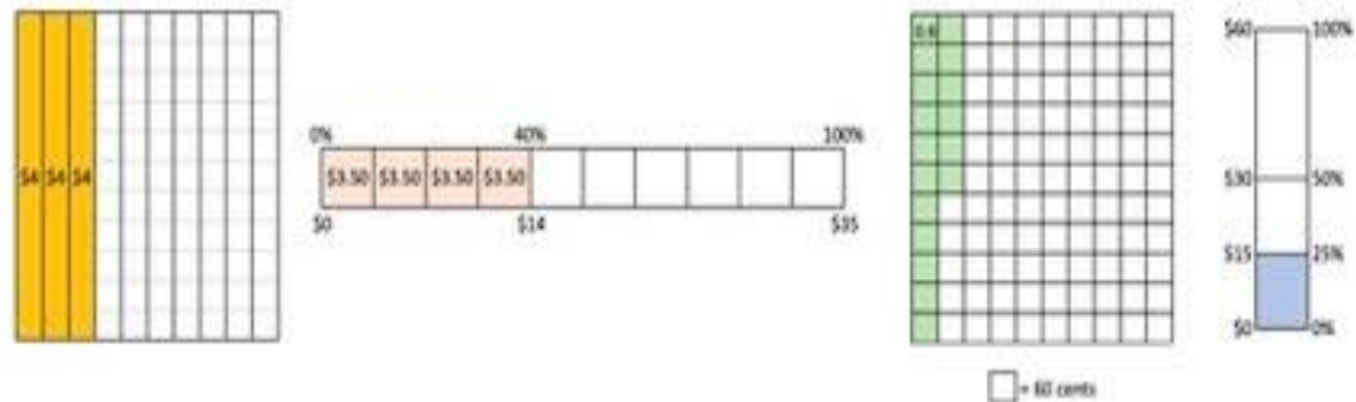

Figure 4. Modeling percentages using strip diagrams and hundreds charts

The CC observed this lesson as part of a POP Cycle. Following the lesson enactment and subsequent debrief, the TC reflected in her journal,

[CC] commented in the debrief that [rotating with specific goals in mind] was apparent and worked really well. She was encouraging in having us continue to explore this strategy. She felt that this deliberate splitting and targeting of the learning goals benefitted [pre-service teachers'] learning. (TC 11/30/17)

In sum, dividing a lesson by goal gave each co-teacher a specific purpose when rotating to pre-service teachers, while also aligning the lesson to the learning goals or big ideas.

Lesson Division by Task. When dividing a lesson by task, each co-teacher focuses on half the tasks and uses this to guide her rotation around the classroom. For instance, if students are working together to solve four tasks, the MT might focus on tasks 1 and 3 and the TC might focus on tasks 2 and 4. Each co-teacher rotates to monitor student thinking on their specific set of tasks, asking follow-up questions and assessing student understanding. Doing so helps to eliminate redundancies of co-teachers' questioning because each co-teacher targets distinctly different tasks.

Another benefit is that each co-teacher can achieve a greater depth of questioning and learn about student reasoning when focusing on a smaller set of tasks. In a post-lesson journal entry, the MT reflected that before co-planning in this way, she was not clear on her purpose when visiting groups of pre-service teachers. She wrote, 'It was neat to rotate with purpose, as l've described the awkwardness that I sometimes feel when I rotate and interrupt [pre-service teachers'] thinking. Sometimes I interrupt them in different ways and feel like it's not consistent' (MT 11/30/17). Lesson division provided an entry point into pre-service teachers' reasoning and a valid reason to interject group work.

We co-planned to divide a percentages lesson by task. Our learning goals for this lesson were: (1) Pre-service teachers will be able to model percentages using strip diagrams and hundreds charts, and (2) Pre-service teachers will be able to mentally compute percentages.

Pre-service teachers worked in groups on four tasks requiring them to calculate the cost of an item after a percentage discount (see Figure 4).

$$
30 \% \text { off } \$ 40
$$

$40 \%$ off $\$ 35$

$15 \%$ off $\$ 60$

$25 \%$ off $\$ 60$

Pre-service teachers taped their solutions around the room according to the task. They then rotated to all four tasks to interpret and analyze each other's strategies for calculating percents.

The MT stood in close proximity to two of the tasks while the TC stood near the other two. Each co-teacher asked targeted questions on her two assigned tasks as groups of pre-service teachers rotated. The TC noticed that she was quickly able to think of questions that built on pre-service teachers' solutions. For instance, I see that these two groups both used strip diagrams to solve this problem, however the strip diagrams look very different to me. What are some of the differences you notice? In the five minutes allotted per task, she perceived it would have been difficult to ask such questions if she had been responsible for all four tasks. In her post-lesson journal, the TC reflected, 'This [strategy] allowed us to each learn our respective tasks better, to ask questions more deeply (compared to teaching alone), and to learn more about [pre-service teachers'] thinking around the task. It also allows us to split the class in half in an organized way' (TC 11/9/17). By focusing on only two tasks, it was easier for the co-teacher to become an 'expert' on those two and ask probing questions compared to teaching alone. While data on the nature of previous questioning styles were not collected in our individual teachings, we relied on our past experiences to notice the change in teacher questioning resulting from this study. This is important since helpful teacher questioning has been documented as an instructional move that supports students' mathematical learning (Krulik et al., 2003; Reinhart, 2000).

Readers should note that regardless of dividing lesson responsibilities by learning goal or by task, the co-teachers anticipate the primary role of each teacher during group rotations. However, just as when planning any lesson, the teachers should anticipate in-the-moment adaptations. For instance, the co-teachers may have planned for one teacher to focus on a (mis)conception that does not arise, and instead students are having difficulty with something unanticipated. Or a teacher may have planned to rotate to ask and answer questions on Task 2 only to find that far more students are encountering difficulty with Task 1 . In situations like these, we advocate for using our teacher expertise and adapting in-the-moment. Yet, as with any lesson, teachers benefit from advanced planning and an attempt to anticipate student solutions and difficulties. 
Equipped with a new strategy for careful co-planning for effective team teaching, we deliberately enacted this strategy throughout our investigation for the remainder of the semester, documenting and analyzing its benefits.

\section{Benefits of Co-Planning for Lesson Division}

To address our second research question, What benefits do co-teachers report when using a co-planning strategy for team teaching?, we report on the benefits of co-planning for team teaching by dividing lesson content. These benefits relate to: explicit learning goals during planning, improved focus during class, maximizing multiple teachers, and fair visitation of students.

Explicit Learning Goals during Planning. Lesson division enhanced our co-planning by making our learning goals more explicit. By determining important concepts prior to class, we planned for in-class interactions to align. After a lesson on integers when we enacted this co-planning strategy, the MT wrote in her journal:

[Having a pre-defined purpose] helps keep the lesson honest with cohesion...We can imagine that [pre-service teachers] have a more clear idea about what the learning goals are if we start the lesson off with them, reiterate throughout, and summarise with them. I have not always known how to let learning goals guide a lesson, so this is neat to learn. (MT $11 / 30 / 17)$

We noted improved alignment between stated and enacted learning goals when planning for team teaching, specifically on how to share learning goals with pre-service teachers, provide tasks aligned with the learning goals, rotate to guide and assess pre-service teachers' thinking towards the goal, and summarise the main takeaways of the lesson.

Improved Focus during Class. Not only did we plan more cohesive lessons with careful co-planning, but we also found more focus when rotating to groups during the enactment of the lesson. In the past, we were sometimes unfocused when listening to, assessing, and questioning pre-service teachers' in-the-moment contributions. By dividing the lesson content, we knew our goals before interacting with pre-service teachers and consequently knew what to look for while monitoring their work. For instance, 'By focusing on two specific tasks instead of four, I was able to note interesting/important aspects of my two tasks pretty quickly...It would have been challenging to do this on the fly with four tasks.' (TC 11/9/17). Each co-teacher had a specific focus and could question pre-service teachers more deeply on a subset of the lesson's learning goals.

Maximizing Multiple Teachers. Careful co-planning gave each co-teacher a designated role in the team taught lesson. As the TC reflected on a POP form, this can 'help in situations where there is more than one adult in the room such as an aide or tutor. Rather than taking full control of a lesson, they can contribute by rotating to groups in search of a particular item related to the content' (TC 11/9/17). In this way, each teacher/tutor/aide plays a role in directing student learning towards the goals of the lesson.

Fair Visitation of Students. We reported that co-planned lesson division encouraged us to visit groups more fairly. We felt this differed from our teaching in the past when we would often spend a large amount of time with one group and not visit others. We also recalled past instances when the TC and MT unknowingly posed the same question to a group. On the second POP form for our CC, we wrote, 'When we didn't split the learning goals or tasks, [TC] would wonder whether [MT] had already talked about this. We don't want to waste time if the other has already discussed it' (MT 11/30/17). We additionally wondered, 'How do we make sure we are getting to all [pre-service teachers] equitably and not redundantly?' (MT 11/30/17). Dividing lesson content allowed us to maximize interactions with pre-service teachers by eliminating repeated questions; we each asked different questions based on task or learning goal. After a second observation with our CC, the TC wrote, 'It seems that we gave each [integer] learning goal (manipulatives and contexts) pretty equal floor time in the lesson' (TC 11/30/17).

In summary, dividing lesson content while co-planning for team teaching allowed us to 'divide and conquer' either by task or learning goal. This coordinated yet distinct focus on important features of the lesson allowed a cohesive approach to teaching.

\section{DISCUSSION}

This first-person research study (Ball, 2000) of a replication of the co-plan/co-teach credential model sought to provide rich accounts of careful consideration of team teaching from an insider's perspective. To do so, each author assumed a different roleTC, MT, or CC-and together enacted credentialing requirements during a fifteen-week long semester in a mathematics content course for future elementary teachers in the USA. Like Gallo-Fox and Scantlebury (2016) noted about co-teaching serving as professional development for co-teachers, we embarked on this research to better understand the co-plan/co-teach model used in teacher credentialing programs at our site.

Our research arose from recognition that teacher educators are expected to prepare pre-service teachers for a co-plan/coteach model that they likely have not experienced themselves. The model involves inducting the TC in a classroom setting under the guidance of a MT and CC. Since pre-service teachers will increasingly be expected to co-teach in their credential program when they become TCs (Yopp et al., 2014), we conjectured that our own first-person research on co-teaching would allow us to 'walk the talk' as described by Kamen et al. (2011) and better understand the co-plan/co-teach credential model. When MTEs implement co-teaching in courses for pre-service teachers, the pre-service teachers benefit from exposure to co-teaching before entering their credential programs (Bacharach \& Heck, 2007; Thousand et al., 2006).

Through this investigation, we found that team teaching allows co-teachers to partition a lesson by either learning goal or task. We followed Pearl et al.'s (2012) recommendation to consider planning as an important element in the successful change to co-teaching. We documented several benefits of careful co-planning for effective team teaching. Past research has documented benefits of co-teaching in general (Bacharach \& Heck, 2007; Bacharach et al., 2010; Birrell \& Bullough, 2005; Cook \& Friend, 1995; 
Duran et al., 2019; Dynak et al., 1997; Ferguson \& Wilson, 2011; Graziano \& Navarrete, 2012; Hiesh \& Nguyen, 2015; Hoppey et al., 2004) but our work extends this understanding by uncovering benefits specific to careful co-planning for effective team teaching in the university setting. These benefits may include greater coherence in the lesson, in both the planning and enactment phases, and a lower student-to-teacher ratio through fairly visiting students and deliberate use of multiple teachers.

Based on our findings, we suggest teachers carefully examine the co-planning phase of lesson planning to determine how to productively implement team teaching in their classrooms. This model of co-teaching requires high levels of trust and collaboration between the two teachers. Teachers should brainstorm while planning to determine how they can construct a lesson to focus on a particular goal or task. In mathematics instruction, this can involve both content and process oriented goals. Conversations between teachers are needed to determine how to strengthen the content and pedagogy of lessons to reach every learner.

Our findings are important as educators aim to practice fair and equitable teaching practices with every student (National Council of Teachers of Mathematics, 2014, Association of Mathematics Teacher Educators, 2017). The first effective math teaching practice highlights the importance of establishing mathematics goals to focus learning, the fourth facilitating meaningful mathematics discourse, and the fifth posing purposeful questions (Association of Mathematics Teacher Educators, 2017). These three practices can be elevated while co-planning for effective team teaching. Moreover, team teaching has been cited as a particularly challenging co-teaching strategy (Thousand et al., 2006). It is important to find meaningful roles for each teacher (Pearl et al., 2012), which can be achieved through careful co-planning. Additionally, many K-12 classrooms have multiple teachers in the classroom-resource teachers, student tutors, and volunteers. Through careful co-planning, each teacher has the potential to play a defined role in productive mathematics instruction.

More research is needed to extend this co-planning strategy to other courses for future mathematics teachers and other subjects. Several limitations of this study will require attention in further research, including the inclusion of the student perspective of various co-teaching strategies, as well as testing and refining lesson division to determine generalizations in other contexts.

Careful co-planning allows co-teachers to make better use of multiple teachers in one classroom. Additionally, it provides an excellent opportunity for novice teachers or aides to play pivotal roles in instruction. Of course, the strategy is also applicable to co-teaching situations in which both teachers are equally experienced, particularly in the university context. Through careful coplanning by dividing lesson content, students benefit because teachers' rotations are deliberate, reducing redundancy and maximizing learning opportunities.

Author contributions: All authors have sufficiently contributed to the study, and agreed with the results and conclusions.

Funding: No funding source is reported for this study.

Declaration of interest: No conflict of interest is declared by authors.

\section{REFERENCES}

Association of Mathematics Teacher Educators. (2017). Standards for Preparing Teachers of Mathematics. amte.net/standards

Bacharach, N., \& Heck, T. W. (2007). Co-teaching in higher education. Journal of College Teaching \& Learning, 4(10), $19-26$. https://doi.org/10.19030/tlc.v4i10.1532

Bacharach, N., Heck, T. W., \& Dahlberg, K. (2010). Changing the face of student teaching. Action in Teacher Education, 32(1), 3-14. https://doi.org/10.1080/01626620.2010.10463538

Ball, D. L. (2000). Working on the inside: Using one's own practice as a site for studying teaching and learning. Lawrence Erlbaum Associates.

Birrell, J. R., \& Bullough Jr, R. V. (2005). Teaching with a peer: A follow-up study of the 1st year of teaching. Action in Teacher Education, 27(1), 72-81. https://doi.org/10.1080/01626620.2005.10463375

Cook, L., \& Friend, M. (1995). Co-teaching: Guidelines for creating effective practices. Focus on Exceptional Children, $28(3), 1$. https://doi.org/10.17161/fec.v28i3.6852

Druken, B. K., \& Marzocchi, A. S. (under review). Co-teaching strategies in action: Selection and implementation in a mathematics content course.

Druken, B. K., Marzocchi, A. S., \& Brye, M. V. (2020). Facilitating collaboration between mathematics methods and content faculty through cross-departmental lesson study. International Journal for Lesson and Learning Studies, 10(1), 33-46. https://doi.org/10.1108/IJLLS-06-2020-0033

Duran, D., Corcelles, M., Flores, M., \& Miquel, E. (2019). Changes in attitudes and willingness to use co-teaching through pre-service teacher training experiences. Professional Development in Education, 46(5), $770-779$. https://doi.org/10.1080/19415257.2019.1634631

Dynak, J., Whitten, E., \& Dynak, D. (1997). Refining the general education student teaching experience through the use of special education collaborative teaching models. Action in Teacher Education, 19(1), 64-74. https://doi.org/10.1080/01626620.1997.10462855

Ferguson, J., \& Wilson, J. C. (2011). The co-teaching professorship: Power and expertise in the co-taught higher education classroom. Scholar-Practitioner Quarterly, 5(1), 52-68. 
Friend, M., Embury, D. C., \& Clarke, L. (2015). Co-teaching versus apprentice teaching: An analysis of similarities and differences. Teacher Education and Special Education, 38(2), 79-87. https://doi.org/10.1177/0888406414529308

Gallo-Fox, J., \& Scantlebury, K. (2016). Coteaching as professional development for cooperating teachers. Teaching and Teacher Education, 60, 191-202. https://doi.org/10.1016/j.tate.2016.08.007

Gleason, J., Livers, S. D., \& Zelkowski, J. (2015). Mathematics classroom observation protocol for practices: Descriptors manual. http://jgleason.people.ua.edu/mcop2.html

Graziano, K. J., \& Navarrete, L. A. (2012). Co-teaching in a teacher education classroom: Collaboration, compromise, and creativity. Issues in Teacher Education, 21(1), 109-126.

Hartigan, B. F. (2014). Early childhood teacher preparation: Using the co-teaching model. Creative Education, 5(8), $641-645$. https://doi.org/10.4236/ce.2014.58076

Hatch, A. (2002). Doing qualitative research in education settings. State University of New York Press.

Hiesh, B., \& Nguyen, H. (2015). Co-teaching, co-leading, co-learning: Reflection on the co-teaching model in practicum. Teaching and Learning Together in Higher Education, 1(14), 1-9.

Hoppey, D., Yendol-Silva, D., \& Pullen, P. (2004). We became teachers together: Understanding collaborative teaching as innovation in unified teacher education. Action in Teacher Education, 26(1), 12-25. https://doi.org/10.1080/01626620.2004.10463309

Kamen, M., Junk, D. L., Marble, S., Cooper, S., Eddy, C. M., Wilkerson, T. L., \& Sawyer, C. (2011). Walking the talk: Lessons learned by university mathematics methods instructors implementing lesson study for their own professional development. In L. C. Hart, A. S. Alston, \& A. Murata (Eds.), Lesson study research and practice in mathematics education (pp. 165-174). Springer. https://doi.org/10.1007/978-90-481-9941-9_13

Krulik, S., Rudnick, J. A., \& Milou, E. (2003). Teaching mathematics in middle school: A practical guide. Allyn and Bacon.

Murphy, C., \& Scantlebury, K. (2010). Coteaching in international contexts: Research and practice. Springer. https://doi.org/10.1007/978-90-481-3707-7

National Council of Teachers of Mathematics. (2014). Principles to actions: Ensuring mathematical success for all.

Pearl, C., Dieker, L. A., \& Kirkpatrick, R. M. (2012). A five-year retrospective on the Arkansas department of education co-teaching project. Professional Development in Education, 38(4), 571-587. https://doi.org/10.1080/19415257.2012.668858

Pratt, S. M., Imbody, S. M., Wolf, L. D., \& Patterson, A. L. (2017). Co-planning in co-teaching: A practical solution. Intervention in School and Clinic, 52(4), 243-249. https://doi.org/10.1177/1053451216659474

Reinhart, S. C. (2000). Never say anything a kid can say! Mathematics Teaching in the Middle School, 5(8), $478-483$. https://doi.org/10.5951/MTMS.5.8.0478

Rexroat-Frazier, N., \& Chamberlin, S. (2019). Best practices in co-teaching mathematics with special needs students. Journal of Research in Special Educational Needs, 19(3), 173-183. https://doi.org/10.1111/1471-3802.12439

Roth, W., Tobin, K., \& Zimmermann, A. (2002). Lessons on and from the dihybrid cross: an activity-theoretical study of learning in coteaching. Journal of Research in Science Teaching, 39(3), 253-282. https://doi.org/10.1002/tea.10018

Rytivaara, A., \& Kershner, R. (2012). Co-teaching as a context for teachers' professional learning and joint knowledge construction. Teaching and Teacher Education, 28(7), 999-1008. https://doi.org/10.1016/j.tate.2012.05.006

Scantlebury, K., Gallo-Fox, J., \& Wassell, B. (2008). Coteaching as a model for preservice secondary science teacher education. Teaching and Teacher Education, 24(4), 967-981. https://doi.org/10.1016/j.tate.2007.10.008

Thousand, J. S., Villa, R. A., \& Nevin, A. I. (2006). The many faces of collaborative planning and teaching. Theory into Practice, 45(3), 239-248. https://doi.org/10.1207/s15430421tip4503_6

Titan EDUCATOR. (n.d.). The focused visit observation form (Unpublished internal document), College of Education, California State University, Fullerton.

Titan EDUCATOR. (n.d.). The POP cycle observation form (Unpublished internal document), College of Education, California State University, Fullerton.

Yopp, R. H., Ellis, M. W., Bonsangue, M. V., Duarte, T., \& Meza, S. (2014). Piloting a co-teaching model for mathematics teacher preparation: Learning to teach together. Issues in Teacher Education, 23(1), 91-111. 
APPENDIX A

Focused Visit Form

CALIFORNIA STATE UNIVERSITY

Multiple Subject Credential Program

Focused Coaching Visit Revised 9.6.16

Focused Coaching Visit instructions: The Clinical Coach will use this form during 15-20 minute focused visit. When the focused visit is complete, the Clinical Coach will fill out the appropriate and selected target and focus areas in Section 2. The clinical coach will email the form to the teacher candidate with in a 24-hour period.

\begin{tabular}{|c|c|c|c|c|}
\hline \multicolumn{5}{|c|}{ Section 1: Candidate Information } \\
\hline & CWID & Subject Area & Semester & Date of Visit \\
\hline Teacher Candidate & School/District & Clinical Coach & \\
\hline Cooperating Teacher & & & \\
\hline Grade Level & $\begin{array}{c}\text { Content Standard and Lesson } \\
\text { Objectives }\end{array}$ & Unit topic & Lesson Title \\
\hline
\end{tabular}

\begin{tabular}{|l|l|l|}
\hline \multicolumn{3}{|c|}{ Learning Goal: To support the development of professional skills and dispositions } \\
\hline \multicolumn{3}{|c|}{ Teaching Performance Expectations } \\
\hline TPE 1: Engaging and Supporting All & TPE 3: Understanding and Organizing & TPE 5: Assessing Student Learning \\
Students in Learning & Subject Matter for Student Learning & TPE 6: Developing as a Professional \\
TPE 2: Creating and Maintaining & TPE 4: Planning Instruction and & Educator \\
Effective Environments for Student & Designing Learning Experiences for All & \\
Learning & Students \\
\hline
\end{tabular}

\begin{tabular}{|c|c|}
\hline $\begin{array}{c}\text { Section 2: } \\
\text { (Based on TPE's) }\end{array}$ & $\begin{array}{c}\text { Observation notes with explicit } \\
\text { support/suggestions from Clinical Coach }\end{array}$ \\
\hline $\begin{array}{l}\text { I. ESTABLISHING A LEARNING SET: } \\
\text { a. presents lesson objectives } \\
\text { b. provides rationale for lesson } \\
\text { c. relates lesson to previous lesson } \\
\text { d. relates material to student interests } \\
\text { e. gains student attention at beginning of lesson }\end{array}$ & \\
\hline $\begin{array}{l}\text { II. LESSON DESIGN AND DEVELOPMENT: } \\
\text { a. starts class promptly and has materials ready } \\
\text { b. relates teacher input to lesson objective } \\
\text { c. emphasizes key points } \\
\text { d. keeps students alert and accountable } \\
\text { e. models task or activity } \\
\text { f. provides guided practice } \\
\text { g. provides corrective feedback } \\
\text { h. provides internal and concluding summaries } \\
\text { i. plans differentiated instruction }\end{array}$ & \\
\hline $\begin{array}{l}\text { III. (Co-)TEACHING STRATEGIES: } \\
\text { a. ensures that strategies are appropriate } \\
\text { b. accommodates different learning styles } \\
\text { c. makes instructional adaptations } \\
\text { d. allows students time to respond } \\
\text { e. probes for clarification, elaboration } \\
\text { f. presents material in a logical sequence } \\
\text { g. provides comprehensible input for all levels of } \\
\text { EL }\end{array}$ & \\
\hline $\begin{array}{l}\text { IV. TEACHER-STUDENT COMMUNICATION: } \\
\text { a. provides clear and concise directions }\end{array}$ & \\
\hline
\end{tabular}


b. uses vocabulary appropriate for all learners

c. uses the English language orally and in writing with no errors

d. supports verbal messages with non-verbal cues

e. demonstrates enthusiasm

\section{CLASSROOM CLIMATE:}

a. effectively manages the classroom

b. creates a positive climate for learning

c. builds positive self-concept

d. encourages cooperation

e. communicates high expectations

\section{ASSESSMENT:}

a. uses progress monitoring during instruction

b. checks for understanding

c. uses informal and formal assessments

\section{Section 3: Target(s) Growth Areas}

$\square$ Held check-in with teacher candidate

$\square$ Held check-in with mentor teacher

Converted form to PDF and emailed teacher candidate on: 


\section{APPENDIX B}

POP Cycle Form

CALIFORNIA STATE UNIVERSITY

\section{Multiple Subject Credential Program}

Pre/Observation/Post Cycle Form Revised 9.2.16

Pre-Observation Instructions: The purpose of this form is to provide the basis of coaching and support for the Teacher Candidate. The Clinical Coach (CC) and the Teacher Candidate (TC) will use this form.

1. The Clinical Coach will email the Teacher Candidate with an agreed upon day and time of observation and will send the POP Cycle Form one week prior to the planned observation.

2. The Teacher Candidate will complete Section 1: Candidate Information on the POP Cycle Form.

3. The Candidate will complete Section 2: Pre-Observation Conference, Part A: Teacher Candidate Reflection Response,

at least 72 hours prior to lesson. The Teacher Candidate will email the POP Cycle Form to the Clinical Coach.

4. The Clinical Coach will review Section 2: Pre-Observation Conference, Part A: Teacher Candidate Reflection Response and will complete Section 2, Part B: Observation Notes and Feedback, at least 48 hours prior to lesson. The Clinical Coach will send this feedback to the Teacher Candidate (either by sending the form or copying this section into an email).

5. Additional instructions follow.

\section{Section 1: Candidate Information}

\begin{tabular}{|c|c|c|c|c|}
\hline \multicolumn{4}{|c|}{ Section 1: Candidate Information } & \\
\hline & CWID & Subject Area & Semester & Date of Visit \\
\hline Teacher Candidate & & & \\
\hline Mentor Teacher & School/District & Clinical Coach & Supervisor \\
\hline Grade Level & & & \\
\hline & $\begin{array}{c}\text { Content Standard and Lesson } \\
\text { Objectives }\end{array}$ & Unit topic & Lesson Title \\
\hline
\end{tabular}

Learning Goal: To coach Teacher Candidates in meeting the TPE expectations. Teaching Performance Expectations

\begin{tabular}{l|l}
\hline TPE 1: Engaging and Supporting All & TPE 3: Understanding and Organizing
\end{tabular}

Students in Learning

TPE 2: Creating and Maintaining

Effective Environments for Student Subject Matter for Student Learning

TPE 4: Planning Instruction and

Designing Learning Experiences for All

Learning
TPE 5: Assessing Student Learning

TPE 6: Developing as a Professional

Educator

\begin{tabular}{|c|c|c|}
\hline $\begin{array}{c}\text { Section 2: Pre-Observation } \\
\text { Conference }\end{array}$ & $\begin{array}{c}\text { Part A: Teacher } \\
\text { Candidate Reflection } \\
\text { Response }\end{array}$ & $\begin{array}{c}\text { Part B: Clinical Coach } \\
\text { Observation } \\
\text { Notes \& Feedback }\end{array}$ \\
\hline $\begin{array}{l}\text { General Lesson Questions } \\
\text { Describe the lesson that will be observed. What } \\
\text { process, if any, did you take to co-plan with your } \\
\text { MT? } \\
\text { Standards/Objectives } \\
\text { How does the lesson objective relate to the content } \\
\text { standard? What will the student be doing to show } \\
\text { progress towards master of the lesson objectives? } \\
\text { Student Engagement } \\
\text { How will you make the lesson relevant to all the } \\
\text { students? } \\
\text { Instructional Planning } \\
\text { Talk about the lesson structure (opening, body, } \\
\text { and closing). } \\
\text { Talk about how the plan uses varied teaching } \\
\text { strategies and differentiated instruction to help } \\
\text { students meet lesson goals. } \\
\text { Talk about how you will progress monitor student } \\
\text { learning and reflect on how the results will inform } \\
\text { your instruction. } \\
\text { Classroom Management }\end{array}$ & $\begin{array}{l}\text { Candidate: Reflect upon the } \\
\text { lesson that will be taught. Use } \\
\text { questions on the left hand to } \\
\text { guide your reflection. }\end{array}$ & $\begin{array}{l}\text { How did the TC use reflection and } \\
\text { feedback to formulate and prioritize } \\
\text { goals for increasing their subject } \\
\text { matter knowledge and teaching } \\
\text { effectiveness? }\end{array}$ \\
\hline
\end{tabular}


Discuss how will you maintain a positive learning environment with a welcoming climate of caring, respect, and fairness?

Discuss specific classroom procedures, including c-

teaching strategies?

What strategies have you considered to prevent

and redirect challenging behaviors?

\section{Closure}

Discuss how you will close your lesson and

describe how this activity will inform the next day lesson.

For your Clinical Coach:

What do you want specific feedback on while the

CC observes?

\begin{tabular}{|c|c|c|}
\hline \multicolumn{3}{|c|}{$\begin{array}{l}\text { Observation Instructions: } \\
\text { 6. During the lesson delivery, the Clinical Coach will complete Section 3: Lesson Delivery, Part A: Clinical Coach Observed } \\
\text { Evidence. The Clinical Coach will meet with the Teacher Candidate immediately following the observation for the post- } \\
\text { observation meeting and complete Section 3: Lesson Delivery, Part B: Shared Reflection. } \\
\text { 7. The Clinical Coach will transcribe the notes into the POP Cycle Form electronically and email it to Teacher Candidate within } \\
24 \text { hours. }\end{array}$} \\
\hline Section 3: Lesson Delivery & $\begin{array}{l}\text { Part A: Clinical Coach } \\
\text { Observed Evidence }\end{array}$ & Part B: Shared Reflection \\
\hline \multicolumn{3}{|l|}{$\begin{array}{l}\text { Introduction } \\
\text { How did the TC introduce the lesson } \\
\text { while connecting to prior knowledge? }\end{array}$} \\
\hline \multicolumn{3}{|l|}{$\begin{array}{l}\text { Body of Lesson } \\
\text { How did the TC facilitate new content? } \\
\text { Consider: development of new } \\
\text { knowledge and skills sets, real world- } \\
\text { application, and interactions }\end{array}$} \\
\hline \multicolumn{3}{|l|}{$\begin{array}{l}\text { Lesson Closure } \\
\text { How did the TC provide opportunities } \\
\text { for students to process and reflect on } \\
\text { the lesson? }\end{array}$} \\
\hline \multicolumn{3}{|l|}{$\begin{array}{l}\text { Making Content Accessible } \\
\text { How did the TC differentiate instruction } \\
\text { for individual student needs and whole- } \\
\text { class instruction? }\end{array}$} \\
\hline \multicolumn{3}{|l|}{$\begin{array}{l}\text { Assessing Student Learning } \\
\text { How did the TC implement entry-level, } \\
\text { progress monitoring or summative } \\
\text { assessments? Did assessments target } \\
\text { lesson objectives? }\end{array}$} \\
\hline $\begin{array}{l}\text { Student Engagement } \\
\text { How did the TC maintain a positive } \\
\text { learning environment with a welcoming } \\
\text { climate of caring, respect, and fairness? } \\
\text { How did the TC manage routine tasks } \\
\text { and student behavior? }\end{array}$ & & \\
\hline
\end{tabular}

Post Observation Conference Instructions:

8. The Teacher Candidate will view the videotape within 48 hours and complete Section 4: Video Analysis and Post Observation Proficiency Scale.

9. While viewing the videotape of the observed lesson, the Teacher Candidate will record evidence into Section 4: Video Analysis and Post Observation Proficiency Scale indicating the elements of their teaching that fall into the categories of "Progressing, Proficient and/or Advanced".

10. Finally, the Teacher Candidate will record action items and goals in Section 5: Action Items and Goals and email the completed POP Cycle Form to the Clinical Coach within 48 hours.

Section 4: Video Analysis and Post Observation Proficiency Scale 


\begin{tabular}{|c|c|c|}
\hline $\begin{array}{c}\text { Progressing } \\
\text { "I still have some work to do!" }\end{array}$ & $\begin{array}{c}\text { Proficient } \\
\text { "I am where I should be, but } \\
\text { not where I want to stay!" }\end{array}$ & $\begin{array}{c}\text { Advanced } \\
\text { "I am teaching like a second } \\
\text { year teacher!" }\end{array}$ \\
\hline & & \\
\hline
\end{tabular}

Section 5: Action Items and Goals 